\title{
Experiência subjetiva e experiência histórica nos diários de David Perlov
}

\author{
Cesar Geraldo Guimarães
}

\begin{abstract}
Não é senão quando damos voltas sobre nossos passos, em outras palavras, não é senão quando perdemos o mundo que começamos a nos encontrar, e a perceber onde estamos e a extensão infinita de nossas relações.
\end{abstract}

(Thoreau - Walden)

E estas coisas, de vida fugaz, entendem que as glorifiques: efêmeras, vêem em nós os salvadores, nós, os mais efêmeros.

(Rilke - A nona elegia)

Resumo: Com base no estudo do processo criador dos diários cinematográficos de David Perlov, e detendo-se sobretudo na sua experiência brasileira, o artigo analisa como a escritura fílmica do cineasta faz das imagens da memória uma superfície de dupla face - como a banda de Moebius - que passa do interior ao exterior, do dentro ao fora, da experiência subjetiva à experiência social e histórica.

Palavras-chave: David Perlov; imagens da memória; autobiografia.

Abstract: Subjective experience and historical experience in the diaries of David Perlov - The paper analyzes the creative process of David Perlov's cinematographic diaries and focuses mainly on his Brazilian experience. The paper analyzes how the filmmaker's script makes a doublesided surface of the images of memory - such as the Moebius band - that goes from the inside to the outside, from the subjective experience to the social and historical experience.

Keywords: David Perlov; memory images; autobiography. 
A primeira parte do Diário 1973-1983, de David Perlov, se abre com uma enigmática divisa: "nas terras da pobreza e do analfabetismo, aqueles que não sabiam assinar os seus nomes colocavam duas cruzes marcadas nas suas fotografias: nome e sobrenome". Essa afirmação, que traduz a consciência do cineasta acerca das desigualdades sociais do país no qual viveu sua infância e juventude - obtida pela infatigável vigília detrás da câmera e pelos comentários em off - vale também como inscrição gravada no pórtico que entreabre ao cineasta (e ao espectador) os territórios da memória. Essa afirmação inicial é o passaporte de Perlov numa longa descida seguindo a correnteza do Letes, o rio do esquecimento.

A letra e a voz do comentário em off são como um precário salvo conduto carregado por aquele que se debruça sobre as próprias imagens, que são para ele tanto um meio de conhecimento - pois lhe permitem desenvolver uma escrita de si na relação com os outros - quanto uma matéria de fascínio e de desapossamento de si (já que ou o espelho é opaco, ou devolve uma imagem outra, irreconhecível, quando o duplo mais oblitera - por repetição - do que revela). No início do primeiro episódio do Diário, logo após convocar as faces amadas das filhas, dizendo-lhes Bom dia para que voltem o rosto para a câmera, ao filmar Yael diante do espelho, Perlov é o primeiro a notar sua ausência na imagem refletida: nós dois no espelho, sob ângulos diferentes. ${ }^{1}$

A construção da identidade (lacunar e hesitante, processo aberto e instável) convive, portanto, com o seu apagamento, por força mesmo do registro cinematográfico: mal algo é retido, enquadrado e sobre-enquadrado (a paisagem da janela, um canto de rua, um cômodo da casa), logo também passa, matéria movente na qual a voz do narrador vem imprimir sua vibração, seu prolongamento no tempo. Dura faina do diário: não basta, portanto, a presença incansável da câmera para nos despertar desse "sono sem sonho" (segundo a expressão de Georges Perec) que constitui a experiência do cotidiano, com seus tempos não marcados, desprovido de acontecimentos, sua insignificância que nos reassegura que, na passagem dos dias, o que muda em nós permanece invisível (o que oferece ao eu o seu grão necessário de ilusão). Como falar então das coisas comuns, como arrancá-las da ganga na qual estão incrustadas e dar-lhes uma língua, um sentido? (PEREC, 1989, p. 11).

É preciso que a própria imagem seja a primeira a reconhecer que ela não é a presença imediata da matéria vivida, mas o que resta de uma operação de subtração, uma composição de vestígios, um arranjo de comentários e visões que, longe de duplicar o habitual e o familiar, os interroga frontalmente, sem se desviar, sabendo desde já que eles se furtam a toda decifração ou exegese. Em suma: é preciso que a imagem seja assinalada por algo mais do que uma ou duas cruzes, que ela passe por uma escritura, um regime peculiar que combina elementos plásticos, geométricos, sonoros, temporais. Que ela possa ser combinada, rearranjada, que sirva a uma transmissão, enfim. Que passe adiante, circule, que lance a vida privada para seu exterior, ainda que só se possa filmar de dentro do apartamento: basta uma janela, uma parede, um muro, um corpo que

1 Optamos por deixar em itálico os comentários em off do cineasta. 
atravessa o campo, mesmo o mais estreito. Basta filmar os ângulos vivos da casa para que se alcance uma escritura fílmica do fora.

Este motivo intriga e assombra Perlov: a ausência da letra e a perda da identidade (domínio da alienação, desmemória, despedaçamento subjetivo no curso do tempo, deslocalização no espaço, desenquadramento mortífero). Aqui a preocupação subjetiva se alia à inquietação política, quando o cineasta volta-se para o mundo dos empregados, como acontece no retorno a São Paulo, vinte anos depois, em fevereiro de 1974: retorno para fazer as pazes com a cidade onde cresceu e para Ihe dizer adeus. Retorno também para se livrar ou se separar do passado - ele narra em off, com a voz superposta à ária de Bach (descoberta há tantos anos, ao ouvir uma rádio católica).

Os planos da cidade, apanhada pelo vidro dianteiro do carro, cedem lugar, bruscamente, a um plano que alcança o ambiente doméstico pelos fundos; um corredor no qual o mundo do trabalho exibe seus objetos e instrumentos: um pano de chão jogado sobre um cano, a vassoura e o rodo encostados na parede, no alto de uma escada, os varais improvisados e os pregadores. (O som da Ária, abaixado, põe em primeiro plano o acanhado pathos da vida ordinária: sobre ela não recairão nem a nostalgia nem o rompimento com o passado). O plano seguinte mostra justamente quem percorre esse espaço e se serve desses utensílios e objetos: a empregada da casa.

Sem se decidir ainda a filmar o irmão, Perlov só consegue filmar, em quatro planos curtos, a jovem empregada negra, quando então comenta: ser doméstica aqui, às vezes, é a única alternativa à miséria. A passagem soaria evidente, se não viesse acompanhada de uma pequena nota, quando, no último plano, delicada e furtivamente, em meio aos seus afazeres, a moça olha para a câmera e o narrador evoca: lembranças antigas: Ana, Carmen... (Tais nomes femininos flutuarão desancorados, significantes puros, associados vagamente à pobreza, ao trabalho, e ao amor, talvez...). Ausência dos rostos nos lugares: as prostitutas do Bom Retiro já desapareceram, restam apenas os nomes próprios: Rosa, Nanci (meu coração fica com vocês, escutamos no último capítulo do Diário revisitado 1990-1999 - Parte 3: Volta ao Brasil). ${ }^{2}$

Ao deixar o Brasil, na passagem por Lisboa (no bonde que lembra aqueles de São Paulo, na adolescência), a Ave-Maria soa como uma evocação dos desaparecidos. Quando nem mesmo a memória conseguir alcançar aparição alguma, somente os nomes restarão (derradeiro traço, sobrevivente): Miguel (o menino, vizinho de bairro na Vila Mariana, em São Paulo, que morrera atropelado pelo bonde), Sofia, Anna (a mãe), dona Guiomar (a mãe de criação), a Muda. A prece poderia valer muito bem como um réquiem: incompleto, apenas esboçado, pois será preciso um segundo retorno ao Brasil e à cidade da infância para que a letra retorne à imagem e uma segunda cena venha rasurar outra, mais longínqua ainda, primitiva (como veremos na última parte do Diário revisitado).

2 Este filme ainda não foi lançado no Brasil. Mencionamos aqui o título que constou da mostra realizada em São Paulo, em 2011, na Cinemateca Brasileira, organizada por Ilana Feldman. 
Em outra passagem, já no sexto capítulo do Diário, na casa do amigo Gabi, sociólogo - um daqueles que quer resolver os problemas dos operários de uma maneira moderna -, depois de filmar (desenquadrando) uma reprodução de Tarsila do Amaral, destacando a palavra operários, Perlov registra atentamente os gestos da empregada, que dispõe com cuidado as taças em uma caixa, contando-as. Diante dessa cena doméstica que talvez permaneça invisível para o sociólogo (que não se vê como patrão), à vontade em sua casa burguesa (no qual uma rede convive com a disposição modernista das escadarias e móveis, ao som dos passarinhos do Brasil), Perlov anota: primeiros passos para a alfabetização. Quando a empregada sai de quadro, o plano dura um pouco mais, e vemos que a caixa traz, por coincidência, a letra "A" estampada em sua lateral. (Letra A, a "rainha do alfabeto", escreveu um dia Drummond naquele seu Boitempo, ao falar dos dias da infância).

A montagem é precisa: partindo do quadro de Tarsila, no segundo andar da casa, e passando pelos diversos rostos (negros, judeus, chineses, artesãos: eles são todos operários, trabalhadores), a câmera desce suavemente pelo espaço aberto e mostra a sala, os sofás, a rede; nos dois planos seguintes surgem a mulher e a filha do amigo; no seguinte, Gabi, que limpa a mesa, e, em seguida, o plano da empregada, ao lado do filho (provavelmente). O primeiro plano desta sequência mostra a empregada do ponto de vista de quem a observa da sala de visitas; o segundo mostra Gabi subindo a escada; e o terceiro, a empregada trabalhando. A montagem é depurada, sem proselitismos nem redundâncias. Nesse mesmo episódio, quando deixa São Paulo rumo a Belo Horizonte (a cidade da infância atormentada), na chegada a Ouro Preto (a cidade do ouro e dos escravos), o cineasta comenta, diante da visão de alguns passantes na estrada: primeiro o pão, depois o cálculo; em seguida, o alfabeto; e, se possível, tudo ao mesmo tempo.

Reiteradamente, explícita ou implicitamente, o trabalho manual é associado ao analfabetismo e à servidão. No último episódio do Diário revisitado, na volta do Rio para São Paulo (outra vez, o retorno aos trilhos da adolescência), os senhores engraxates que trabalham na Estação da Luz aparecem como escravos, assim como a empregada do hotel ou o condutor do trem. Diante do rosto do engraxate negro, de cabelos brancos, que parece dormir acordado (por causa das poucas horas de sono que lhe restam), a pergunta pela identidade (qual o seu nome?; qual sua idade?) é sucedida por uma afirmação repetida: toda a vida para servir. Servir bem. Servir a quem? E se o engraxate acorda (de quais sonhos? De qual outra vida?) não é senão para falar com a linguagem da obediência.

Se é certo que o gesto de filmar eu mesmo para mim mesmo (como é enunciado logo no início do primeiro episódio do Diário) é verdadeiramente libertador diante de todas as imposições do cinema industrial, ele não garante, contudo, que o eu também fique imune no pequeno quadro que consegue recortar da vastidão das relações que o mundo exterior nos oferece. O cinema - sobretudo em sua vertente documentária - permite, enfim, que a alteridade do mundo venha rebater sobre o eu, expondo-o ao que o ultrapassa e desafia sua compreensão: o mundo parece grande; a tirania, infinita, 
e você no centro de tudo (ouvimos ao final do Diário revisitado 1990-1999 - Parte 3: Volta ao Brasil). Essa é a descoberta que logo faz aquele que acaba de retornar. Estrangeiro em toda parte, não-reconciliado.

Qualquer que seja o mundo - exterior ou interior -, ele começa por uma divisão. Não se faz um mundo com átomos; é preciso ao menos um clinâmen, e um mundo começa escreve Jean Luc Nancy (2004, p. 17) - e, com ele, a partilha com o que dele se separa: próximo e estrangeiro. Uma inclinação para o outro, uma relação, uma declinação para o comum, eis o que faz um mundo. Em todo lugar estrangeiro, é o lema que Perlov toma a Odetta, sabemos bem, mas que significa também: em tudo o que é familiar, reencontrar o estranho (para não esquecer Freud). A escritura dessa autobiografia fílmica poderia ser entendida então como uma inclinação para o outro, estrangeiro ou familiar; num ou noutro caso, uma alterbiografia. As imagens impressas na memória, acordadas por aquele que revê o real de onde partiram um dia, acordam alteradas. E, se uma primeira operação permite aproximar uma coisa da outra (o reencontro com os lugares vividos e a lembrança que deles se conserva), como uma criança que copia um desenho com um papel vegetal, em luta contra o modelo que lhe foge sob a transparência, há momentos em que o retorno se vê diante de algo cujo reconhecimento é perturbador. Nesse tipo de reconhecimento, a divisão dilacera, ímpar, sem que nenhuma metade possa apaziguar o que permanece como resto, ruína lisa, inexpugnável, desafiando toda incisão que queira gravar um traço (qualquer que seja) como assinatura do sujeito. Desapossamento, retirada de si como única condição para escapar de um retorno ameaçador.

Uma linha semiapagada liga a inscrição que abre os diários ao trabalho da memória e ressalta, em particular, o vínculo entre a imagem, a letra e o comentário. Não é coincidência, portanto, que, já em Belo Horizonte, diante do túmulo da mãe, Perlov se sinta incomodado pela mudança na grafia do sobrenome materno gravado na lápide (Perlof ao invés de Perlov): o traço do F lembra, imageticamente, uma cruz. Para o irmão, Aarão, a visita ao túmulo da mãe era um modo de não a deixar desprotegida e de preservar sua memória. Mas era também, ambiguamente, um modo dos filhos se protegerem: deixá-la só poderia acarretar uma desgraça, comenta o cineasta. Quando se deparar com este lugar uma segunda vez, uma década mais tarde, Perlov encontrará a grafia corrigida (coisa providenciada pelo irmão, Aarão, a seu pedido). Agora a letra pode, enfim, tomar o lugar da imagem, se libertar do seu encantamento (mas foi preciso, antes, fazer uma nova visita à casa da infância assombrada, como mostraremos a seguir).

Esse gesto singelo traduz, na verdade, um longo e reiterado esforço que percorre os diários: o lentíssimo e persistente trabalho da escritura cinematográfica, em sua dupla jornada: primeiro, distender o quanto pode esse instante fugidio no qual o cone invertido da memória, com sua finíssima ponta de agulha - segundo o conhecido desenho de Bergson -, toca o presente (para logo se tornar coisa passada) e, depois, reunir os fragmentos, ordenálos, conceder-lhes uma escala, uma impossível medida para tudo o que permanece sem 
medida: os afetos que a própria imagem preserva e aciona, dispara e, ao mesmo tempo, recolhe. Presença duplamente diferida: a do presente, registrada em seu transcorrer, fugidia, e acompanhada do comentário, que vem sempre depois, destacado da imediaticidade do aparecer dos eventos: trabalhado, escrito, reescrito, destacado em sua materialidade.

É o comentário que faz da imagem, ela mesma, um evento. Todo registro, do passado ou do presente, se vê assim projetado para mais adiante pelo comentário, o que só aumenta a não-coincidência do sujeito consigo mesmo. Tanto melhor. Maior a clivagem, mais pronunciada a necessidade de se por em relação, de multiplicar as mediações, o que faz do paradoxo a figura definidora das relações entre imagem e memória, como bem notou Ilana Feldman (2011, p. 45): "Perlov deixa de apenas contextualizar os momentos da filmagem para ver nesses momentos passados (tornados presentes) pontes com sentimentos, sensações e presságios que habitam seu presente (tornado passado)".

O que Perlov faz é distender o tempo - para que o instante pontual se torne uma cena enquadrada -, mas sem precisar que nela se passem coisas. Ausência de dramaturgia: basta que alguém ocupe momentaneamente o quadro ou passe por ele. O que vale para o interior das casas (a sua e a dos amigos) e dos hotéis vale também para o espaço exterior, desde que uma figura humana apareça numa janela. Na primeira volta a São Paulo, a rua da infância, com um dos seus lados tomado pelas casas destruídas, surge como um rosto mutilado. Para aquele que ama tanto a frontalidade quanto a deriva, como filmar se não há como nem compor um retrato nem percorrer as fachadas das casas? Como convocar as faces amadas, a não ser então pelo que as palavras ou o canto evocam? O pequeno portrait de Belka, a jovem descendente de armênios que vem visitá-lo em São Paulo, traz consigo o que ela ainda preserva da língua materna: enquanto a moça canta, a inóspita paisagem urbana é iluminada pela primavera longínqua, ancestral à maneira de um fora-de-campo absoluto -, e pelos equívocos do amor, que os poemas cantaram desde sempre. É porque algo ainda se transmite, passa de um a outro - entre quem filma e é filmado - no momento mesmo da tomada, que o Diário 1973-1983 nada tem de nostálgico, ainda que faça o incontornável inventário das perdas e das mudanças impostas pela passagem do tempo.

Na segunda volta à cidade da adolescência, as janelas vizinhas já não exibem mais as figuras de outrora (para onde foram? Onde se esconderam?). Os planos se sucedem, à espera de uma face conhecida (uma única seria suficiente!), e mostram a vida por detrás das fachadas, sem rosto, nos fundos do prédio: roupas estendidas no varal, um estacionamento, o telhado precário das casas miúdas e pobres, alguém que capina um terreno. Em meio às buzinas, emerge o fragmento de uma música sertaneja tocada no rádio: "mas o destino, cruel...". Quem diria que o Maktub poderia se manifestar assim, em formas tão banais? No reencontro com Fauzi, na segunda visita a São Paulo, Perlov discorda da crença do amigo de infância no destino. Fauzi, libanês, dizia: "nós os orientais (árabes e judeus) - ressalta Perlov - cremos naquilo que estava escrito". Porém, no último 
episódio do Diário revisitado, na segunda volta a Belo Horizonte, diante da casa da infância (tão desfigurada), o cineasta indaga se essa história, que mistura a pobreza, o sofrimento e a doença mental, não seria mesmo regida pelo destino. Talvez pudéssemos dizer que sim, desde que a fatalista expressão "estava escrito" seja substituída por "estava inscrito", remetendo ao conjunto de índices com os quais o sujeito se depara, e cujo sentido o excede em muito. Trata-se, portanto, menos de um passado que governaria e decidiria o presente de antemão, desde sempre, do que uma operação que leva os eventos do passado a retornarem no futuro, alterados, reescritos. Não que o passado fosse, com isso, compreendido (e pacificado, finalmente), pois trata-se sobretudo de uma operação de pensamento (com seu pathos impresso na voz, que grava o comentário) e não de uma explicação capaz de recobrir a verdade dessa inquietação que leva o cineasta a retornar aos lugares antigos (ele mesmo permanece cindido, rachado pelos tempos e imagens díspares que o habitam).

A escrita do diário (como gênero) seria, a rigor, infinita (tecido compósito, tramado por anos a fio), não fosse a necessidade de estabelecer, a cada vez, uma marca (pequena que seja) no encadeamento dos dias que correm, como condição para a inscrição da memória: designar este ou aquele acontecimento, silencioso ou ruidoso; apanhar a vista de uma janela (mesmo sendo aquela de todos dias); percorrer e filmar as ruas (à deriva ou pela porta entreaberta de um café); e fazer do comentário uma escrita incessante, depurada, que monta e remonta essa vasta coleção de registros. No início do Diário 1973-1983, quando muda de apartamento, em maio de 1977, em Tel Aviv, o cineasta filma os aposentos esvaziados (mas repletos de lembranças) e indaga o que as filhas viam do ponto de vista das janelas do seu quarto, enquanto cresciam: o tênue equilíbrio da luz ao entardecer, ou uma realidade mais dura, que as incomodava? No cinema de Perlov, o deliberado e persistente movimento de voltar-se para o cotidiano que transcorre anonimamente, nele interrogando o que é habitual por meio do meticuloso trabalho da escritura fílmica, convive sempre com a aparição do passado, revisitado e ressignificado pela montagem.

Contudo, a despeito dessa voluntária convocação - promovida pelo comentário das experiências passadas, há algo em algumas imagens que insiste, teimosamente, em retornar, contra a vontade daquele que relembra: algo que resta, um traço do real. Daí a supersticiosa advertência da sua mãe de criação, que o cineasta carrega consigo: Nunca refaça seus próprios passos, seus pés podem se queimar e você pode não voltar a andar. (A recomendação de Dona Guiomar é mencionada pela primeira vez quando Perlov, acompanhado da filha Yael, retorna à casa onde morou em Paris, ainda jovem). Parece-nos que, mais do que simplesmente vencer a superstição ou ultrapassar um interdito, o retorno à casa da infância traz algo de mais difícil ainda, na vizinhança do trauma.

A primeira menção à casa da infância, em Belo Horizonte, surge no capítulo inaugural do Diário 1973-1983, quando Perlov recebe os amigos Julio e Fela. Sentados no chão da sala do novo apartamento, um microfone à sua frente, Júlio lê seus poemas; Perlov 
menciona um incidente no qual, encontrado por Fela desacordado - ela o julgara morto -, pedira à amiga que Ihe cantasse uma canção do seu país, o Uruguai. Ele pede que ela relembre. Fela então canta "Angelitos negros", cujos versos tocam especialmente o cineasta: "pintor que pintas iglesias, píntame angelitos negros / ¿por qué nunca te acordaste de pintar un ángel negro? / Pintor si pintas con amor por qué desdeñas su color?". Essa passagem ganha uma ressonância peculiar ao ser associada à outra, no sexto capítulo do Diário 1973-1983, quando, nos jardins da Praça da Liberdade, em Belo Horizonte, Perlov filma uma garotinha vestida de branco, de cabelos claros (cuidadosamente penteados pela mãe), que posa para uma foto. Nesse momento ele lembra o termo que D. Guiomar, sua mãe de criação, negra, utilizava para se referir a crianças como esta: anjinhos.

Ele conta que, menino, perguntara a Dona Guiomar se no céu havia anjos negros como ela. (A câmera se move sutilmente e desenquadra a criança para mostrar as garis negras que observam a cena). Outra vez, Perlov mostra como a desigualdade social no Brasil se manifesta numa relação enganosa de identificação, como ocorre com a empregada que cuida dos móveis dos patrões como se fossem seus; do motorista que se vê como dono do carro do patrão; da mãe de criação, negra e protestante, que se espelha nos valores dos brancos. Impedida de ser afirmada, a diferença só pode ser recalcada. Contra isso, o diário procede a um trabalho crítico que cinde em dois o sujeito autobiográfico e o põe diante do mundo de tal modo que ele, por atrito, possa tomar distância das suas próprias identificações. O comentário e a montagem tornam-se, assim, procedimentos que descolam o imaginário da imagem.

No primeiro episódio do Diário 1973-1983, o plano que sucede à canção mostra Fela com o encarte de um disco na mão, que trouxera de presente para os amigos Perlov e Mira. Entretanto, não escutamos nem o disco nem o que ela canta, apenas o comentário de Perlov, que nos diz ouvir somente os tambores obsessivos que retumbam na sua mente; os sons de tambores nos ensaios para o carnaval na esquina da casa em que morou, menino, e que iam até tarde da noite. Essa casa, no entanto, só aparecerá bem mais tarde, no sexto episódio do Diário 1973-1983. No primeiro retorno a Belo Horizonte, em 1983, Perlov retarda ao máximo a chegada. Partindo de São Paulo de carro, junto com Mira, o amigo Gabi e a esposa, o grupo faz paradas em Ibiúna (para ver a festa de São Sebastião), Ouro Preto e Tiradentes. E quando Perlov chega diante da casa da infância, ela é filmada em um único plano (com profundidade de campo) do outro lado da rua (a justa distância), de frente para o cruzamento. Movimentos suaves (e talvez hesitantes) da câmera, um para a esquerda e para o alto, outro que desce e se aproxima, e um terceiro para a direita (descentrando levemente o prédio, mais atento aos transeuntes), são acompanhados de comentários lacônicos, entrecortados, secos: minha casa durante dez anos / O pátio invisível / As janelas do salão de bilhar / Insanidade mental / Tragédia / Os ratos se multiplicando noite após noite.

No plano seguinte, que apanha o céu e os edifícios da Praça Sete, do alto para baixo, o narrador enuncia seu desejo de partir no dia seguinte. (A visão da casa, brevíssima, 
já fora suficiente ou ela guardava um excesso que não poderia ser visto nem mais de perto nem por mais tempo?). Os planos seguintes mostram a visita ao cemitério onde a mãe foi enterrada. Uma sucessão de lápides negras satura o campo. Desta vez, entre a casa da infância e a lápide do túmulo da mãe, a articulação entre os planos é tão elíptica quanto o comentário. Será preciso mais tempo para atravessar um limiar que não está apenas no espaço.

Quase uma década depois, ao final do Diário revisitado 1990-1999 - Parte 3: Volta ao Brasil, Perlov retorna a Belo Horizonte e filma a casa da infância uma segunda vez, refazendo até mesmo o trajeto anterior pela cidade: na Praça da Liberdade, casais namoram, moças leem romances nos bancos; em frente à Igreja de São José, Perlov filma os passantes que fazem o sinal da Cruz (hoje, em menor número, ele observa). Em frente à igreja católica situava-se, outrora, a igreja protestante frequentada por Dona Guiomar, substituída pelo edifício Acaiaca, a exibir o rosto do índio guarani, emprestado à lenda; perto dali, no quarteirão vizinho, no Cine Brasil, ele assistira a seu primeiro filme ( $A$ vida de Jesus), quando Ihe chamou a atenção a cor que Judas vestia: o amarelo da vergonha e da desgraça. Mas as cores lhe mostraram também - desde cedo - que um filme é algo construído, inventado, um artefato.

Em contraste com o único plano dedicado à casa da infância no último capítulo do Diário 1973-1983, a nova visita (no Diário revisitado 1990-1999 - Parte 3: Volta ao Brasil) é marcada por planos meticulosamente filmados, submetidos a uma complexa montagem. A primeira tomada, frontal, se dá à noite, quando se acendem as primeiras luzes e os anúncios luminosos na fachada do prédio. Em seguida, vemos as lojas do térreo: uma farmácia, uma lanchonete, uma ótica, um restaurante de comida a quilo e uma entrada para o salão de bilhar (no segundo andar, que dá para o pátio interno). Depois de dois planos no interior da farmácia, sem diálogos, e outro no exterior (vê-se uma mulher na janela), estamos já dentro do pátio (embora o espectador só se dê conta disso depois), diante de uma porta construída com velhas e frágeis placas de madeira. Do alto, uma lâmpada de luz mortiça, pendurada pelo fio elétrico, ilumina um depósito de coisas abandonadas. A câmera começa um movimento ascensional que percorre a porta: sobe aos poucos e nos mostra uma segunda porta, trancada, até alcançar, no terceiro andar, uma parede de alvenaria, com uma janela de vidro. (Surgem as vozes do terceiro movimento do Réquiem de Gabriel Fauré: Libera me Domine). Os vidros da janela não filtram luz alguma, não há nenhum vitral: adentramos um sepulcro.

Em seguida, numa rápida mudança de ponto de vista, um corte nos situa no segundo andar, e vemos o pátio embaixo: à direita, a porta de madeira; à esquerda, um varal com poucas roupas, uma banheira de plástico para bebês, um vaso de planta sobre uma cadeira. (Os objetos sem dono não são sempre o vestígio de uma vida abandonada?). O plano seguinte muda outra vez o ângulo: situados dentro do quartinho fracamente iluminado, vemos agora o que víamos do alto: uma vassoura caída, a banheirinha de plástico 
(enquanto a música prossegue). Como em um torvelinho que se inicia suavemente, nosso olhar é conduzido outra vez para a janela de vidro, no terceiro andar, e, em seguida, a câmera faz um movimento de 360 graus, girando em torno das paredes do pátio. Estamos quase que soterrados, o alto não nos liberta. Libera me Domine, ressoa a música. O espaço enquadrado gira; crise, sofrimento insuportável: o espaço é assombrado pelas terríveis lembranças da doença da mãe. Ela não sabia se os gritos vinham de fora ou de dentro dela, diz o comentário.

Feito o giro pelo espaço enclausurado (à procura de uma fuga?), vemo-nos brutalmente diante de parede lisa, imagem nua sem inscrição alguma, a não ser a voz que a denomina: nada para dizer. Espaço cinza, uniforme, sem significado. Nada para ver. Nada para olhar para trás. Imagem tumular, aquela da qual não se pode retirar nada; impenetrável ao olhar, ela barra o corpo vidente. Visto o impossível de ver, aquele que queria olhar até o fim pode se retirar (mas não é nem Lázaro nem Orfeu). Libera me Domine.

O cemitério abre-se numa alameda. As lápides não tomam mais o campo. A inscrição agora é límpida, a letra $\mathrm{V}$, restituída, tomou o lugar do $\mathrm{F}$ que lembrava a cruz. (Escutamos o barulho do cinzel que fez a incisão da letra na dura matéria do tampo da sepultura?). A letra contra a cruz. A mãe, enfim, protegida. Pode-se, agora, ir novamente ao encontro da fachada da casa: plano noturno, janelas de luzes apagadas, o prédio quase submerso na escuridão urbana, os passantes são quase sombras. O cineasta permanecerá em vigília. A mais difícil das noites. Amanhece, a luz do poste em frente ao prédio ainda brilha. Do lado de fora, a cidade, entre o resto da noite e o princípio do dia, se transfigurou em imenso pátio da memória. Surge um rapaz na janela (sempre as janelas e os rostos, mesmo apanhados de longe) seguido de um plano que mostra um carregador, um senhor negro, sentado em seu carrinho (em breve as barracas dos vendedores ambulantes tomarão o passeio). As sombras cedem lugar aos habitantes da cidade. A vida ordinária emerge do Letes. O banal, Maktub, a vida transfigurada, entre o assombro e o correr dos dias (Perlov lembra de Fauzi, o amigo libanês).

Tantos anos, tantas imagens para se livrar do passado. Liberto, enfim. Os primeiros raios do sol chegam aos trilhos do metrô, na antiga estação de onde um dia, com dez anos, ele partira para São Paulo: retirado das trevas. A mãe (Anna) ainda correra atrás do trem; Dona Guiomar (a mãe de criação) permanecera imóvel. O metrô passa, filma-se a sua desaparição no quadro. Tomada frontal do prédio da antiga estação. Livra-me, Senhor, da morte eterna.

Ao contrário do emblema do primeiro episódio do Diário 1973-1983, não é mais o caso de retornar para se livrar do passado. Trata-se, antes, de livrá-lo de si. Desprendido, liberto, finalmente, o passado pode retornar, projetado diante dos nossos olhos. E com ele retornam as vidas, todas elas, únicas e inumeráveis. 
Cesar Geraldo Guimarães é professor associado do Departamento de Comunicação e do Programa de Pósgraduação em Comunicação da UFMG e Pesquisador do CNPq. cesargg6@gmail.com

\section{Referências}

FELDMAN, I. David Perlov: epifanias do cotidiano. In: FELDMAN, I.; MOURÃO, P. (Org). David Perlov: epifanias do cotidiano. São Paulo: Centro da cultura judaica, 2011.

NANCY, J. La communauté désoeuvrée. Paris: Christian Bourgois, 2004.

PEREC, G. L'infra-ordinaire. Paris: Seuil, 1989.

Artigo recebido em novembro de 2016 e aprovado em fevereiro de 2017. 